\title{
Hedging voyage charter rates on illiquid routes
}

\section{Andrés G. Mirantes}

IES de Candás,

Carretera del Faro 17, 33430 Candás,

Asturias, Spain

Email: andres_g@telecable.es

\section{Javier Población}

\author{
Banco de España, \\ C/Alcalá 48, 28014, \\ Madrid, Spain \\ Email: javier.poblacion@bde.es
}

\section{Gregorio Serna*}

Facultad de Ciencias Económicas y Empresariales,

Universidad de Alcalá,

Plaza de la Victoria, 2,

28802 - Alcalá de Henares, Madrid, Spain

Email: gregorio.serna@uah.es

*Corresponding author

\begin{abstract}
Freight prices are heterogeneous, and not all the routes have the same liquidity of spot or futures prices; therefore, sometimes there are problems related to one, or more, route hedges. In this paper, we develop a methodology to hedge the price risk of one route using other routes' futures contracts. The main result of this paper is that we can hedge, with a great fit, the price risk of one route using other routes' futures contracts. The hedging results obtained with our methodology outperform those obtained with standard simple regression procedures.
\end{abstract}

Keywords: freight rate; world scale; WS; hedging methodology; Kalman filter.

Reference to this paper should be made as follows: Mirantes, A.G., Población, J. and Serna, G. (2020) 'Hedging voyage charter rates on illiquid routes', Int. J. Shipping and Transport Logistics, Vol. 12, No. 3, pp.197-211.

Biographical notes: Andrés G. Mirantes is a high school teacher, teaching mathematics in Asturias, Spain. He holds a Bachelors degree in Mathematics from the University of Oviedo, Spain, and a PhD in Banking and Finance from the University of Castilla-La Mancha, Spain. His work has been published in several journals on Finance and Transportation.

Javier Población is a Banco de España Economist and European Central Bank Principal Expert. He holds a Bachelors degree in Physics from Complutense University of Madrid and a PhD in Banking and Finance from the University of 
Castilla-La Mancha, Spain. He works in baking supervision and financial stability. His work has been published in several journals on Finance and Transportation.

Gregorio Serna is an Associate Professor of Financial Economics at the Department of Economics and Business Management at the University of Alcala, Spain. He holds a PhD in Economics from Carlos III University of Madrid. He teaches Financial Economics at the undergraduate and graduate levels. His work has been published in several journals on Finance and Transportation.

This paper is a revised and expanded version of a paper entitled 'Hedging time charter illiquid route prices. A study about freight price dynamics' presented at the 6th Research Workshop on Energy Markets, Valencia, Spain, 27 March 2015.

\section{Introduction}

Freight markets have experienced significant growth during recent years. Consequently, not only researchers and academics but also practitioners are focusing increasingly on valuation techniques and hedging procedures applied to spot and futures freight prices traded on the market.

Freight rate dynamics have been widely studied in the literature. For example, the relationship between spot and futures prices is analysed in Glen et al. (1981) and Hale and Vanags (1989). The existence of a unit root in freight rates is analysed in Veenstra and Franses (1997), Tvedt (2003), Adland et al. (2006) and Poblacion (2017), among others, and the relationship between freight rates and oil prices is analysed in Alizadeh and Nomikos (2004).

The seasonal behaviour of freight rates has been studied in Alizadeh and Kavussanos (2001, 2002) and Poblacion (2015). These authors find that freight prices show a strong seasonal behaviour that has implications in terms of transportation policy and ship owners' cash flow and charterers' costs.

There are also studies that propose factor models to characterise freight rate dynamics. A simple Ornstein-Uhlenbeck model for freight rates is proposed in Tvedt (2003), whereas a model for supply and demand is proposed in Adland and Strandenes (2007). More complicated factor models that value option contracts for time charter prices are proposed in Adland and Koekebakker (2004) and Rygaarda (2009). Prokopczuk (2011) shows that the Schwartz and Smith (2000) two-factor model provides the best performance for freight rate futures pricing and hedging. Poblacion (2015) extends the two-factor model by Schwartz and Smith (2000), in the context of freight rates, to incorporate stochastic seasonality.

More recently, Poblacion and Serna (2018), within the framework of the multi factor models proposed by Schwartz and Smith (2000), show that freight rates corresponding to different routes have a common long-term trend.

Adland et al. (2017a) propose a multivariate model for regional ocean freight rates, where the natural logarithm of a specific route freight rate is the sum of a non-stationary common market factor and a stationary moving average factor, allowing for regional 
deviations from the common market factor. If the common market factor is interpreted as the global market average, both factors are observable and the model can be estimated using the standard ARIMA methodology.

Concerning risk hedging, the traditional methodology was based on the minimum variance hedge ratio, introduced by Johnson (1960), Stein (1961), Ederington (1979) and Hull (2012). This method consists of estimating the hedge ratio that minimises the price changes in the investor's total position, based on a simple regression framework. However, as stated in Kavussanos and Nomikos (2000), this method ignores the well-documented time-varying distributions shown by many assets and the existence of a long-run cointegration relationship between asset and futures prices. To overcome these problems, Kavussanos and Nomikos (2000) propose a vector error correction model (VECM) for the relationship between spot and futures returns, with a GARCH structure for the error term, allowing for time-varying hedge ratios. Kavussanos and Visvikis (2010) also study the hedging effectiveness of time-varying hedge ratios. Adland et al. (2017a) also present a method for hedging regional price risk, based on their factor model.

In this paper, we focus on freight rate hedging. Specifically, we propose a simple methodology to hedge the price risk of one (not liquid enough) route using other more liquid routes' futures contracts; the results of this methodology overcome other traditional methodologies such as the simple regression procedure proposed by Hull (2012). For our method, we estimate a joint model with a common long-term trend for pairs of freight rates, according to the model proposed by Poblacion and Serna (2018) that is applied to carry out the hedge. As stated above, Adland et al. (2017a) also present a method for hedging regional price risk. However, we address the problem from a different perspective. Firstly, we do not need to make assumptions about the observability of the model factors, because we estimate the model parameters by means of the Kalman filter method, which allows for non-observable factors. Secondly, the hedging procedure presented by Adland et al. (2017a) is based on the maximisation of a utility function, with constant positive risk aversion. However, we employ a purely financial approach that approximates a certain futures price series by means of a linear combination of other futures price series, which results in a minimising problem where the averages and covariances are estimated theoretically, based on the proposed model for the stochastic behaviour of freight rates. Thirdly, we estimate the common long-term factor for pairs of routes based on the freight rates from both routes, without assuming that the common factor is a global market average.

This paper then contributes to the extant literature in several ways. Firstly, we present a method for hedging the price risk of one (not liquid enough) route using other more liquid routes' futures contracts, based on a common long-term trend model for pairs of freight rates, taking into account the long-run relationship between both freight rates. This common long-term trend model is not based on a simple regression procedure, but is a coherent model for the relationship between spot and futures prices. Secondly, we do not make assumptions about the observability of the model factors (as in Adland et al., 2017a), because we estimate the model parameters by means of the Kalman filter method.

The main result of the paper is that we can hedge, with a great fit, the price risk of one route using other more liquid routes' futures contracts. This result has important implications in terms of freight price hedging. 
This paper is organised as follows: Section 2 presents the dataset used in this paper. In Section 3, we present and estimate the joint models with and without a common long-term trend for pairs of freight rates. Thereafter, in Section 4 we present a simple methodology to hedge one route's freight prices with futures from other routes. These results are better than those from other traditional methodologies such as the one presented by Hull (2012). Finally, the paper concludes with a summary and discussion in Section 5.

\section{The dataset}

In this paper we focus on crude oil and product tankers. Product tankers can move refined (clean) products, such as gasoil, gasoline and kerosene, whereas crude oil tankers are designed to load dirty products. However, product tankers can also load many dirty products, such as crude and heavy fuel oil, bearing the cost of tank cleaning for avoiding the possibility of the next cargo becoming contaminated by the previous (dirty) one. ${ }^{1}$

The types of crude oil tankers include the following categories: Very Large Crude Carriers (200,000 DWT or greater), SuezMax (125,000-199,999 DWT), Aframax (85,000-124,999 DWT) and Panamax (55,000-84,999 DWT). In the case of product tankers we can find the following categories: long range 'LR2' (85,000-124,999 DWT), long range 'LR1' (60,000-84,999 DWT), medium range (42,000-59,999 DWT) and handysize $(25,000-41,999$ DWT).

All the tanker routes considered in this paper are voyage charter contracts. A voyage charter contract is a legal contract in which a ship-owner agrees to carry a particular load on a certain voyage on a particular ship, for a certain sum of money.

The dataset used in this paper includes weekly observations of the forward prices of the world scale (WS) listed by Baltic (http://www.balticexchange.com) for two routes: TC2 and TD5. Table 1 displays the details of these routes, such as the loading port, the unloading port and the type of ship. ${ }^{2}$

Table 1 Routes details

\begin{tabular}{lcc}
\hline & $T C 2$ & $T D 5$ \\
\hline Loading port & Rotterdam & Bonny \\
Unloading port & New York & Philadelphia \\
Ship type & Medium range (MR) & SuezMax \\
Capacity (MT) & 37,000 & 130,000 \\
Time lag (days) & 14 & 31 \\
\hline
\end{tabular}

Note: The table shows details about the routes.

As is well known, the WS is an index based on an annual benchmark (or flat rate). However, the data that we use in the paper are expressed as US dollar and cents per metric tonne, after converting the index by means of the annual conversion factor. Therefore, we are considering the payment, in USD, of transporting one tonne by a particular ship travelling a particular route. All associated costs, such as the bunker cost, the crew cost and the port cost, are included in this payment, except for the insurance costs. 
Specifically, for the two routes described above, TC2 and TD5, we have data from 26 February 2009 to 25 February 2014, which include 262 weekly observations. For these two routes we have forward prices with maturity from one to five months (F1, F2, F3, F4 and F5, where F1 is the forward contract for the first month after the closest maturity, F2 is the contract for the second month, and so on) and from three quarters to five quarters, (Q3, Q4 and Q5, where Q3 is the third quarter after the current one, Q4 is the fourth quarter after the current one and Q5 is the fifth quarter after the current one). The main descriptive statistics, the mean and volatility, of these variables are shown in Table 2 .

Table 2 Descriptive statistics

\begin{tabular}{|c|c|c|c|c|}
\hline & \multicolumn{2}{|c|}{$T C 2$} & \multicolumn{2}{|c|}{ TD5 } \\
\hline Period & \multicolumn{2}{|c|}{26 February 2009-25 February 2014} & \multicolumn{2}{|c|}{26 February 2009-25 February 2014} \\
\hline \multirow[t]{2}{*}{ Nr. observ. } & \multicolumn{2}{|c|}{262} & \multicolumn{2}{|c|}{262} \\
\hline & Mean & Volatility & Mean & Volatility \\
\hline $\mathrm{F} 1$ & 19.0 & $43 \%$ & 8.9 & $34 \%$ \\
\hline $\mathrm{F} 2$ & 19.0 & $28 \%$ & 8.9 & $25 \%$ \\
\hline $\mathrm{F} 3$ & 19.0 & $21 \%$ & 9.0 & $20 \%$ \\
\hline $\mathrm{F} 4$ & 19.0 & $19 \%$ & 8.9 & $19 \%$ \\
\hline F5 & 18.9 & $18 \%$ & 8.9 & $18 \%$ \\
\hline Q3 & 18.9 & $21 \%$ & 8.9 & $13 \%$ \\
\hline Q4 & 19.0 & $18 \%$ & 9.0 & $11 \%$ \\
\hline Q5 & 19.0 & $17 \%$ & 9.0 & $13 \%$ \\
\hline
\end{tabular}

Notes: The table shows the mean and volatility of spot and forward prices of world scale (WS) for two routes (TC2 and TD5) during the period 26 February 2009 to 25 February 2014.

\section{Stochastic factor models to characterise freight price dynamics}

In this section, we present the joint model for pairs of freight rates proposed by Poblacion and Serna (2018) that will be used as the basis for developing the methodology to hedge the price risk of one route using other routes' futures contracts.

This joint model for pairs of freight rates proposed by Poblacion and Serna (2018) is based on the classical two-factor model by Schwartz and Smith (2000). In this model, each log-spot price $\left(X_{i t}\right)$ is assumed to be the sum of two stochastic factors: a short-term deviation $\left(\chi_{i t}\right)$, which is different for each freight price, and a common long-term equilibrium price level $\left(\xi_{t}\right)$, plus a deterministic seasonal component, $\alpha_{t}$. Therefore, the $\log$-spot price for each freight price $\left(X_{i t}\right)$ will be $X_{i t}=\xi_{t}+\chi_{i t}+\alpha_{t}, i=1,2$. The SDEs of the factors for this joint model with a common long-term trend (under the risk-neutral measure) are: 


$$
\begin{aligned}
& d \xi_{t}=\left(\mu_{\xi}-\lambda_{\xi}\right) d t+\sigma_{\xi} d W_{\xi t}^{*} \\
& d \chi_{i t}=\left(-\kappa_{i} \chi_{i t}-\lambda_{\chi i}\right) d t+\sigma_{\chi i} d W_{\chi i t}^{*}, i=1,2 \\
& d \alpha_{t}=2 \pi \varphi \alpha_{t}^{*} d t \\
& d \alpha_{t}^{*}=-2 \pi \varphi \alpha_{t} d t
\end{aligned}
$$

where $d W_{\xi t}^{*}, d W_{\chi 1 t}^{*}$ and $d W_{\chi 2 t}^{*}$ can show any correlation structure, resulting in three correlation parameters.

In this model, $\mu_{\xi}$ and $\sigma_{\xi}$ represent the trend and volatility, respectively, of the common long-term factor, whereas $\kappa_{i}$ and $\sigma_{\chi i}$ represent the speed of adjustment and volatility, respectively, of each short-term factor. $\lambda_{\xi}$ and $\lambda_{\chi i}$ are the 'risk premiums' for the long- and short-term factors, respectively.

This model also accounts for the seasonal effect noted by Alizadeh and Kavussanos (2001, 2002) and Sorensen (2002), among others. Therefore, in the above model, the seasonal effect is included as a deterministic seasonal trigonometric component $\left(\alpha_{t}\right)$; whereas $\alpha_{t}^{*}$ is the other seasonal factor that complements $\alpha_{t}$, and $\varphi$ is the seasonal period.

This joint model with a common long-term trend will be compared with a joint model for pairs of freight rates without a common long-term trend, i.e., with different long-term trends for each freight rate.

These joint models with and without a common long-term trend require two additional parameters to account for differences in price levels, $C_{1}$, and to account for the way that the common long-term trend affects the price dynamics of each commodity, $C_{2}$.

Table 3 presents the results of the estimation of the joint models with and without a common long-tern trend described above. The dataset used in the estimation consists of weekly observations of WS TC2 and TD5 freight futures prices described in the data section.

Table 3 Estimation results

\begin{tabular}{lcc}
\hline & Without a common long-term trend & With a common long-term trend \\
\hline$C_{1}$ & $-20.9078^{* * *}(0.8485)$ & $-33.7713(1.2631)$ \\
$C_{2}$ & $-2.9326(0.0000)$ & $1.6120^{* * *}(0.0000)$ \\
$C_{\xi}$ & - & $0.0368(0.0473)$ \\
$C_{\alpha}$ & $0.5257^{* * *}(0.0450)$ & $0.9945^{* * *}(0.0000)$ \\
$C_{\alpha}{ }^{*}$ & $-0.0820^{* *}(0.0391)$ & $-0.2368(0.0000)$ \\
$\mu_{\xi 1}$ & $-0.2136(1.8331)$ & $0.1681^{* *}(0.0723)$ \\
$\mu_{\xi 2}$ & $-0.6640(1.7134)$ & - \\
$\kappa_{1}$ & $0.0719^{* * *}(0.0000)$ & $4.0819^{* * *}(0.0000)$ \\
$\kappa_{2}$ & $0.0162^{* * *}(0.0019)$ & $0.0017^{* * *}(0.0000)$ \\
$\varphi$ & $1.0085^{* * *}(0.0028)$ & $1.0279^{* * *}(0.0057)$ \\
\hline
\end{tabular}

Notes: The joint model with and without a common long-term trend for WS TC2 and

TD5. The table presents the results for the Schwartz and Smith (2000) two-factor model with deterministic seasonality applied to pairs of WS freight rates (TC2-TD5), with and without assuming a common long-term trend. Standard errors are in parentheses. The estimated values are reported with *denoting significance at $10 \%, * *$ denoting significance at $5 \%$, and $* * *$ denoting significance at $1 \%$. 
Table 3 Estimation results (continued)

\begin{tabular}{|c|c|c|}
\hline & Without a common long-term trend & With a common long-term trend \\
\hline$\sigma_{\xi 1}$ & $4.7622 * * *(0.0000)$ & $0.1603 * * *(0.0131)$ \\
\hline$\sigma_{\chi 1}$ & $5.0532 * * *(0.0000)$ & $0.5383 * * *(0.0366)$ \\
\hline$\sigma_{\xi 2}$ & $3.9295 * * *(0.0000)$ & - \\
\hline$\sigma_{\chi^{2}}$ & $3.9844 * * *(0.0000)$ & $0.0278 * * *(0.0029)$ \\
\hline$\rho_{\xi 1 \chi 1}$ & $-0.9995 * * *(0.0000)$ & $-0.3245 * * *(0.1005)$ \\
\hline$\rho_{\xi 1 \xi 2}$ & $0.5862 * * *(0.0000)$ & - \\
\hline$\rho_{\xi 1 \chi 2}$ & $-0.5843 * * *(0.0000)$ & $-0.4626 * * *(0.1580)$ \\
\hline$\rho_{\chi 1 \xi 2}$ & $-0.5844 * * *(0.0000)$ & - \\
\hline$\rho_{\chi 1 \times 2}$ & $0.5827 * * *(0.0000)$ & $0.6752 * * *(0.1044)$ \\
\hline$\rho_{\xi 2 \times 2}$ & $-0.9985 * * *(0.0000)$ & - \\
\hline$\lambda_{\xi 1}$ & $0.2070(1.8975)$ & $0.1333(0.0730)$ \\
\hline$\lambda_{\chi 1}$ & $-0.5612(2.0036)$ & $0.5898 * *(0.2261)$ \\
\hline$\lambda_{\xi 2}$ & $-0.4008(1.9198)$ & - \\
\hline$\lambda_{x^{2}}$ & $0.3668(1.9449)$ & $-0.0040(0.0000)$ \\
\hline$\sigma_{\eta}$ & $0.0360 * * *(0.0000)$ & $0.0345 * * *(0.0004)$ \\
\hline Log-L & $12,878.10$ & $13,184.87$ \\
\hline AIC & $12,830.10$ & $13,146.87$ \\
\hline SIC & $12,744.46$ & $13,079.08$ \\
\hline
\end{tabular}

Notes: The joint model with and without a common long-term trend for WS TC2 and

TD5. The table presents the results for the Schwartz and Smith (2000) two-factor model with deterministic seasonality applied to pairs of WS freight rates (TC2-TD5), with and without assuming a common long-term trend. Standard errors are in parentheses. The estimated values are reported with *denoting significance at $10 \%, * *$ denoting significance at $5 \%$, and $* * *$ denoting significance at $1 \%$.

The values of the Schwarz and Akaike information criteria, SIC and AIC, respectively, are shown at the bottom of Table 3. Both information criteria are defined as specified in Poblacion and Serna (2018), and the fit is better when the SIC or the AIC is higher. The results show that both specifications (with and without a common long-term trend) exhibit a similar fit, although the model with a common long-term trend exhibits slightly higher values for both information criteria.

The relative fit of the models to our freight price series can be assessed by evaluating their predictive ability. The in-sample predictive ability of the joint models with and without a common long-term trend is presented in Table 4 for the pair under study, WS TC2 and TD5. Thus, given that the predictive ability of the two models is very similar, we can conclude that both freight prices exhibit the same long-term trend. Consequently, because the joint model that assumes a common long-term trend is the simplest one, we do not need a second long-term factor when jointly modelling the freight price series considered. 
Table 4 In-sample predictive ability (RMSE)

\begin{tabular}{cccccc}
\hline & \multicolumn{3}{c}{ TC2 } & & \multicolumn{2}{c}{ TD5 } \\
\cline { 2 - 3 } \cline { 5 - 6 } \cline { 5 - 6 } F1 & With & Without & & With & Without \\
F2 & $2.2 \%$ & $2.3 \%$ & & $0.9 \%$ & $0.9 \%$ \\
F3 & $1.7 \%$ & $1.8 \%$ & & $0.8 \%$ & $0.7 \%$ \\
F4 & $1.4 \%$ & $1.7 \%$ & & $0.8 \%$ & $0.7 \%$ \\
F5 & $1.4 \%$ & $1.5 \%$ & & $0.9 \%$ & $0.5 \%$ \\
Q3 & $1.6 \%$ & $1.6 \%$ & & $1.1 \%$ & $0.5 \%$ \\
Q4 & $1.6 \%$ & $1.6 \%$ & & $1.5 \%$ & $0.8 \%$ \\
Q5 & $1.4 \%$ & $1.2 \%$ & & $1.1 \%$ & $0.6 \%$ \\
\hline
\end{tabular}

Notes: The table presents the root mean square error (RMSE) as the percentage of its mean (RMSE mean per.) to compare the in-sample predictive power of the Schwartz and Smith (2000) two-factor model with deterministic seasonality for the pair WS TC2-WS TD5 freight rates between the specifications with and without a common long-term trend.

\section{Hedging one route's risk using other routes' futures contracts}

In this section, we develop a methodology to hedge the price risk of one route using other routes' futures contracts. Suppose that there are futures contracts available on routes 0,1 , $2, \ldots, K$. Let $F_{t, T}^{(i)}$ be the futures price for route $i$, traded at time $t$ and maturing at time $t+T$. The goal is to approximate a certain futures price using other futures prices. Specifically, we will approximate the futures price $F_{t, T_{0}}^{(0)}$ using other futures prices, $F_{t, T_{1}}^{(1)}$, $\ldots, F_{t, T_{N}}^{(N)}(N \leq K)$, plus a position in the risk-free asset. The best approximation, in regards to least squares, will be given by the solution of the following problem:

$$
\min _{\gamma, \alpha_{1}, \ldots, \alpha_{N}} E\left[\left(F_{t, T_{0}}^{(0)}-\gamma-\sum_{j=1}^{N} \alpha_{j} F_{t, T_{j}}^{\left(i_{j}\right)}\right)^{2}\right]
$$

This is the approach used in Hull (2012), who considers only the case $j=1$.

The most typical case is one in which we want to hedge a spot position in an asset with other spot positions in other assets, i.e., $T_{0}=T_{1}=\ldots=T_{N}=0$. For example, suppose we have data for the WS spot freight prices for routes TC2, TC14 and TC16 and suppose we want to hedge the first one, TC2, in 15 months with the others, TC14 and TC16. In this case, we would run a regression of the TC2 spot freight prices on a constant and TC14 and TC16 spot freight prices. Suppose that we obtain coefficients of 11.63, 0.0297 and 0.0337 for $\gamma$ and $\alpha_{1}$ (TC14) and $\alpha_{2}$ (TC16), respectively. These results would imply that, for each unit of TC2, we must keep 11.63 monetary units and take long positions in 0.0297 and 0.0337 units of the 15-month TC14 and TC16 futures contracts.

The above problem is a simple regression problem. If $Z=\left(1 F_{t, T_{j}}^{(1)} \ldots F_{t, T_{N}}^{(N)}\right)$ is the vector of regressors, then the coefficients are: 


$$
\left(\begin{array}{c}
\gamma \\
\alpha_{1} \\
\cdots \\
\alpha_{N}
\end{array}\right)=E\left[Z^{\prime} Z\right]^{-1} E\left[Z^{\prime} F_{t, T_{0}}^{(0)}\right] \gamma
$$

Therefore, the only thing left to do is to compute the averages and covariances of the futures prices. There are two ways of computing those averages and covariances, empirically and theoretically. The empirical method is the approach followed by Hull (2012) and consists simply of computing the averages and covariances using a sample of futures prices and estimating the expected values and the covariances using the sample averages and covariances. ${ }^{3}$ The theoretical method requires a theoretical model for the stochastic behaviour of the commodity prices under consideration. The specific procedure for carrying out the hedge in the case of the theoretical method is explained next.

The model for the stochastic behaviour of freight rates proposed in expression (1) can be represented using the following linear stochastic differential system:

$$
\left\{\begin{array}{l}
d X_{t}=\left(\mu+A X_{t}\right) d t+R d W_{t} \\
S_{t}^{(0)}=\exp \left(C_{0} X_{t}\right) \\
S_{t}^{(1)}=\exp \left(C_{1} X_{t}\right) \\
\cdots \\
S_{t}^{(k)}=\exp \left(C_{k} X_{t}\right)
\end{array}\right.
$$

where $X_{t}$ is a vector of state variables, $S_{i}^{(i)}$ is the price at time $t$ for freight rate $i, \mu, A, R$ and $C_{i}$ are deterministic parameters independent of $t$, and $W_{t}$ is an $n$-dimensional canonical Brownian motion (i.e., all components are uncorrelated, and the variance is equal to unity). All the analyses below will be conditional on $X_{0}$, that is assumed to be known, and, in practice, it is estimated using the Kalman filter [see Harvey (1989) and Poblacion and Serna (2016), among others, for details about the Kalman filter method].

The solution of that problem is:

$$
X_{t}=e^{A t}\left(X_{0}+\int_{0}^{t} e^{-A s} \mu d s+\int_{0}^{t} e^{-A s} R d W_{s}\right)
$$

Therefore, the expected value and the variance of $X_{t}$ are:

$$
\begin{aligned}
& E\left[X_{t}\right]=e^{A t}\left(X_{0}+\int_{0}^{t} e^{-A s} \mu d s\right) \\
& \operatorname{Var}\left[X_{t}\right]=e^{A t}\left(\int_{0}^{t} e^{-A s} R R^{\prime}\left(e^{-A s}\right)^{\prime} d s\right)\left(e^{A t}\right)^{\prime}
\end{aligned}
$$

Thus, the futures price can be computed as:

$$
F_{t, T}=\exp \left[d(T)+C(T) X_{t}+\eta_{t}\right]
$$

where $d, C$ and the variance of the noise $\left(\eta_{t}\right)$ are known. Let $\sigma_{\eta}^{2}=\operatorname{Var}\left(\eta_{t}\right)$. 
The log-futures price has an expected value of $d(T)+C(T) E\left[X_{t}\right]$ and a variance of $C(T) \operatorname{Var}\left(X_{t}\right) C(T)^{\prime}+\sigma_{\eta}^{2}$. so that it is easy to compute the expected value of the futures price.

Suppose that we have two futures prices: $F_{t, T}=\exp \left[d(T)+C(T) X_{t}+\eta_{t}\right]$ and $F_{v, V}=\left[d(V)+C(V) X_{v}+\eta_{v}^{*}\right]$. Then, the logarithm of their product is $\left[d(T)+C(T) X_{t}+\eta_{t}\right]+$ $\left[d(V)+C(V) X_{v}+\eta_{v}^{*}\right]$, which is normally distributed with the mean:

$$
d(T)+C(T) E\left[X_{t}\right]+d(V)+C(V) E\left[X_{v}\right]
$$

And the variance, considering the usual hypothesis of independence between the noises of the system and the average:

$$
\begin{aligned}
& \operatorname{Var}\left(\eta_{t}\right)+\operatorname{Var}\left(\eta_{v}^{*}\right)+\operatorname{Cov}\left(\eta_{t}, \eta_{v}^{*}\right)+C(V) \operatorname{Var}\left[X_{v}\right] C(V)^{\prime} \\
& +C(T) \operatorname{Var}\left[X_{t}\right] C(T)^{\prime}+C(T) \operatorname{Cov}\left(X_{t}, X_{v}\right) C\left(V^{\prime}\right)
\end{aligned}
$$

The variances of the noises of the average and the state and the covariance of the averages are known.

The only thing left to do is to compute the covariance: $\operatorname{cov}\left(X_{t}, X_{v}\right)$. Let us assume, without a loss of generality, that $v<t$, then:

$$
X_{t}=e^{A(t-v)}\left[X_{v}+\int_{0}^{t-v} e^{-A s} \mu d s+\int_{0}^{t-v} e^{-A s} R d W_{v+s}\right]
$$

Finally, considering that the noise is independent of the current state:

$$
\operatorname{Cov}\left(X_{t}, X_{v}\right)=e^{A(t-v)} \operatorname{Var}\left(X_{v}\right)
$$

We now consider an application of the hedging procedure described above. Suppose that we want to hedge the WS freight price corresponding to route TC2 using the WS freight prices for route TD5. ${ }^{4}$ The goal is to hedge the series Q5 for the first route (TC2) with the series Q5 for the other route (TD5). We have decided to use the series Q5 because series with longer maturities typically tend to have a greater number of missing values. The first step is to estimate a joint model with a common long-term trend for the pair WS TC2-TD5 (already performed in the previous section). The second step is to estimate the coefficients of the regression in expression (2) for the WS TC2 freight prices on a constant and WS TD5 freight prices, using the model procedure described above. In this application, the hedge is performed weekly.

The results of the hedging procedure are summarised in Table 5. It is worth noting that the root mean squared error (RMSE) decreases when we move from the simple regression hedge to the model hedge (a reduction of $48.05 \%$ ). The time series evolution of the target futures price (WS TC2) and the simple regression and model hedge series are depicted in Figure 1. In order to compare the predictive accuracy of both alternatives, i.e., the classical regression procedure by Hull (2012) and the model regression based on the common long-term trend model, we have employed the Diebold and Mariano (1995) test. Let $e_{1 t}$ and $e_{2 t}$ be the quadratic errors associated with the classical regression procedure by Hull (2012) and with the procedure based on the common long-term trend model respectively, and let $d_{1 t}=e_{2 t} \sim e_{1 t}$. The Diebold and Mariano (1995) statistic has been calculated by means of a regression of $\mathrm{d} 1 \mathrm{t}$ on an intercept, using heteroskedasticity and autocorrelation robust standard errors. The intercept is estimated as -1.5484 , with a 
p-value of 0.0001 , indicating that we are able to reject the null hypothesis of equality between both quadratic errors.

In order to check the performance of our hedging procedure with other freight rate futures series, we have repeated the hedging experiment using freight rates for two clean routes. Specifically, the goal is to hedge the series Q5 for route TC14 with the series Q5 for route TC6, with data from 18 May 2012 to 31 December 2013 (95 weekly observations). The results indicate that we obtain a reduction of $12.27 \%$ in the RMSE with the model hedge based on the common long-term trend model, with respect to the standard regression approach. Furthermore, we have also repeated the hedging experiment using two different dirty routes: TD5 and TD16. Specifically, the goal is to hedge the series Q5 for route TD5 with the series Q5 for route TD16, with data from 26 February 2009 to 28 December 2012 (209 weekly observations). In this case the results indicate that we obtain a reduction of $14.34 \%$ in the RMSE with the model hedge based on the common long-term trend model, with respect to the standard regression approach. However, as stated above, the reduction in the RMSE with routes TC2 and TD5 was $48.05 \%$. Therefore, at least with these freight rates series, we cannot say that we obtain better hedging results with futures prices of the same type (TC-TC or TD-TD). Perhaps other factors, such as the characteristics of the routes or the specific time-series used in the experiment, are playing an additional role in explaining the results, apart from the futures prices type (clean or dirty). ${ }^{5}$

Table 5 Hedging results

\begin{tabular}{lcc}
\hline & Simple regression hedge & Model hedge \\
\hline Standard deviation & 1.4617 & 0.7135 \\
RMSE & 1.4562 & 0.7565 \\
\hline
\end{tabular}

Notes: The table shows two metrics (standard deviation and root mean squared error, RMSE) to compare the hedging results from the simple regression and the proposed model hedge procedures.

Figure 1 Target futures and regression and model hedge series

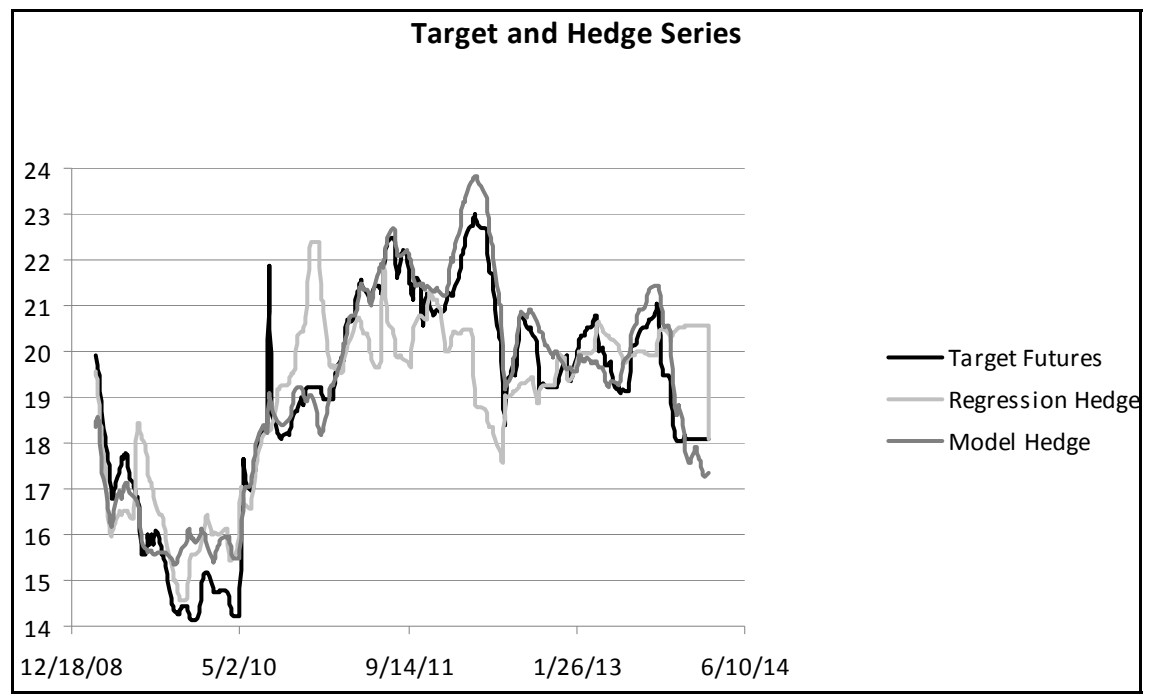


Finally, it is worth noting that the advantage of the model hedge compared to the regression hedge is that, apart from the better fit, the model hedge allows the incorporation of the hedge futures series that has not yet been used in the estimation.

\section{Conclusions}

Since there is a large number of routes and types of freights, freight prices are heterogeneous, and not all the routes have the same liquidity for spot or futures prices. Specifically, there are routes with scarce liquidity, especially in longer term futures contracts. Therefore, sometimes there are problems related to one, or more, route hedges. These problems can be overcome by using the hedging procedure presented in this paper.

As stated, the main result obtained in this paper is that we can hedge, with a great fit, the price risk of one route using other routes' futures contracts. This result has important implications in terms of freight price hedging, especially when we want to hedge a route that does not have futures contracts or if they are illiquid.

The fact that route prices share a common long-term trend, as stated in Poblacion and Serna (2018), allows managers to hedge the price risk of one certain route when there are not futures prices associated with that route or when futures contracts are not liquid enough, using other more liquid routes' futures contracts.

Suppose, for example, that we want to hedge a freight of route WS TC2 that will occur in the long-term (or a long maturity futures contract of this route); let the long-term indicate five quarters (Q5), and let there be no futures (or assume they are not liquid enough) for this route, but the futures exist and are liquid enough for route WS TD5. The idea is to hedge the freight of route WS TC2 that will occur in the long-term using the futures of route WS TD5.

As stated in this paper, the simple regression procedure proposed by Hull (2012) is an alternative to carry out the hedge; nevertheless, we have developed a more sophisticated hedging strategy based on the estimation of a joint model with a common long-tern trend for both freight rates (WS TD5 and WS TC2).

The hedging procedure in managing this situation is as follows.

Step 1 Estimate a joint model with a common long-term trend for routes WS TC2 and WS TD5.

Step 2 Estimate a regression of WS TC2 on a constant and WS TD5, based on the theoretical variance-covariance matrix, derived from the joint model with a common long-term trend.

The results of this paper show that the hedging procedure presented here (based on the joint model with a common long-term trend) is more accurate because it uses all the information of the common long-term dynamics showed by both routes, while the simple regression procedure does not.

As stated in the Introduction, one of the advantages of our methodology with respect to Adland et al. (2017a) is that we do not need to make assumptions about the observability of the model factors, because we estimate the model parameters by means of the Kalman filter method, which allows for non-observable factors. However, on the other hand, it must be said that the Kalman filter method is not as simple as the standard 
ARIMA methodology used by Adland et al. (2017a), which makes the later easier to implement.

Finally, as suggestions for future research, it would be interesting to investigate the factors affecting the empirical performance of our methodology, i.e., why the empirical performance is better with certain pairs of routes than with other pairs (i.e., if they are of the same type, TC-TC or TD-TD, the characteristics of the routes, the specific time-series employed in the estimation, etc.). Furthermore, it would be interesting to perform an empirical analysis of the relative performance of models like ours, based on a purely financial approach that approximates a certain futures price series by means of a linear combination of other futures price series, and models based on the maximisation of a utility function (as Adland et al., 2017a).

\section{Acknowledgements}

This paper is the sole responsibility of its authors. The views represented here do not necessarily reflect those of the Banco de España. We thank Ryan Monkerud, Rocio Moraga, Juan Manuel Martín and two anonymous referees. We thank Repsol YPF, in particular, for its support. We also acknowledge the financial support of the Spanish Ministerio de Economía, Industria y Competitividad Grant ECO2017-89715-P. Any errors that remain are, however, entirely the authors' own.

\section{References}

Adland, R. and Koekebakker, S. (2004) 'Modelling forward freight rate dynamics - empirical evidence from time charter rates', Maritime Policy \& Management, Vol. 31, No. 4, pp.319-335.

Adland, R. and Strandenes, S. (2007) 'A discrete-time stochastic partial equilibrium model of the spot freight market', Journal of Transport Economics and Policy, Vol. 41, No. 2, pp.189-218.

Adland, R., Benth, F.E. and Koekebakker, S. (2017a) 'Multivariate modelling and analysis of regional ocean freight rates', Transportation Research Part E: Logistics and Transportation Review, Vol. 113, No. C, pp.194-221.

Adland, R., Hansson, D. and Wense, L. (2017b) 'Valuing cargo flexibility in oil transportation', Maritime Policy \& Management, Vol. 44, No. 7, pp.803-814.

Adland, R., Koekebakker, S. and Sødal, S. (2006) 'Are spot freight rates stationary?', Journal of Transport Economics and Policy, Vol. 40, No. 3, pp.449-472.

Alizadeh, A. and Kavussanos, N. (2001) 'Seasonality patterns in dry bulk shipping spot and time charter freight rates', Transportation Research Part E: Logistics and Transportation Review, Vol. 37, No. 6, pp.443-467.

Alizadeh, A. and Kavussanos, N. (2002) 'Seasonality patterns in tanker spot freight markets', Economic Modelling, Vol. 19, No. 5, pp.747-782.

Alizadeh, A. and Nomikos, N.K. (2004) 'Cost of carry, causality and arbitrage between oil futures and tanker freight markets', Transportation Research Part E: Logistics and Transportation Review, Vol. 40, No. 4, pp.297-316.

Diebold, F.X. and Mariano, R.S. (1995) 'Comparing predictive accuracy', Journal of Business and Economic Statistics, Vol. 13, No. 3, pp.253-263.

Ederington, L.H. (1979) 'The hedging performance of the new futures markets', The Journal of Finance, Vol. 34, No. 1, pp.157-170. 
Ederington, L.H. and Salas, J.M. (2008) 'Minimum variance hedging when spot price changes are partially predictable', Journal of Banking \& Finance, Vol. 32, No. 5, pp.654-663.

Glen, D., Owen, M. and Van der Meer Reviewed, R. (1981) 'Spot and time charter rates for tankers, 1970-1977', Journal of Transport Economics and Policy, Vol. 15, No. 1, pp.45-58.

Hale, C. and Vanags, A. (1989) 'Spot and period rates in the dry bulk market: some tests for the period 1980-1986', Journal of Transport Economics and Policy, Vol. 23, No. 3, pp.281-291.

Harvey, A.C. (1989) Forecasting Structural Time Series Models and the Kalman Filter, Cambridge University Press, Cambridge, UK.

Hull, J. (2012) Options, Futures and Other Derivatives, Prentice Hall, New Jersey.

Johnson, L. (1960) 'The theory of hedging and speculation in commodity futures', Review of Economic Studies, Vol. 27, No. 3, pp.139-151.

Kavussanos, M.G. and Nomikos, K. (2000) 'Constant vs. time-varying hedge ratios and hedging efficiency in the BIFFEX market', Transportation Research Part E: Logistics and Transportation Review, Vol. 36, No. 4, pp.229-248.

Kavussanos, N. and Visvikis, I.D. (2010) 'The hedging performance of the capesize forward freight market', in International Handbook of Maritime Business, Edward Elgar Publishing, Northampton, MA, USA.

Poblacion, J. (2015) 'The stochastic seasonal behavior of freight rate dynamics', Maritime Economics \& Logistics, Vol. 17, No. 2, pp.142-162.

Poblacion, J. (2017) 'Are recent bulk shipping prices stationary?', Maritime Economics \& Logistics, Vol. 19, No. 4, pp.650-666.

Población, J. and Serna, G. (2016) 'Is the refining margin stationary?', International Review of Economics and Finance, July, Vol. 44, pp.169-186.

Poblacion, J. and Serna, G. (2018) 'A common long-term trend for bulk shipping prices', Maritime Economics \& Logistics, Vol. 20, No. 3, pp.421-432.

Prokopczuk, M. (2011) 'Pricing and hedging in the freight futures market', Journal of Futures Markets, Vol. 31, No. 5, pp.440-464.

Rygaarda, J. (2009) 'Valuation of time charter contracts for ships', Maritime Economics \& Logistics, Vol. 36, No. 6, pp.525-544.

Schwartz, E.S. and Smith, J.E. (2000) 'Short-term variations and long-term dynamics in commodity prices', Management Science, Vol. 46, No. 7, pp.893-911.

Sorensen, C. (2002) 'Modeling seasonality in agricultural commodity futures', The Journal of Futures Markets, Vol. 22, No. 5, pp.393-426.

Stein, J. (1961) 'The simultaneous determination of spot and futures prices', The American Economic Review, Vol. 51, No. 5, pp.1012-1025.

Tvedt, J. (2003) 'A new perspective on price dynamics of the dry bulk market', Maritime Policy \& Management, Vol. 30, No. 3, pp.221-230.

Veenstra, A.W. and Franses, P.H. (1997) 'A co-integration approach to forecasting freight rates in the dry bulk shipping sector', Transportation Research Part A: Policy and Practice, Vol. 31, No. 6, pp.447-458. 


\section{Notes}

1 See the excellent discussion on these issues provided by Adland et al. (2017b).

2 TC and TD stand for 'tanker clean' and 'tanker dirty' respectively.

3 Ederington and Salas (2008) present a way of improving the classical regression of spot price increments on futures price increments, to calculate the optimal hedge ratio. The improvement consists of incorporating into the regression, as an independent variable, the expected change in the spot price, measured by the futures-spot price spread. The inconvenience of the approach by Ederington and Salas (2008) is that their method calculates the averages and covariances in the regression using a sample of spot and futures prices and estimating the expected values and the covariances using the sample averages and covariances.

4 We may think that in principle it is questionable that freight rates corresponding to different (clean and dirty) routes can be comparable. However, from a financial perspective the comparison could make sense. A shipping company could chose to hedge a certain clean (dirty) route with freight futures from a different dirty (clean) route just because the later is more liquid. By means of the example in our paper we try to show that even in this case the proposed hedging strategy, based on the common long-term trend model, can be effective.

5 In order not to make the paper unnecessarily long, the results of the estimation of the model with a common long-term trend the pairs of freight rates TC14-TC6 and TD5-TD16 are not presented in the paper, but the are available from the authors upon request. 